DOI: $10.17805 /$ zpu.2015.3.22

\title{
Ценностные ориентации предпринимателей с разным психологическим типом деловой активности*
}

\author{
В. П. ПОЗНЯКОВ \\ (Институт психологии РАН)
}

В статье излагаются результаты исследования ценностных ориентаций предпринимателей с разным психологическим типом деловой активности. Исследование проводилось в 2009 г. В опросе приняли участие 106 предпринимателей. В качестве характеристик деловой активности предпринимателей в данном исследовании использовались следующие показатели: оценка собственных возможностей повышения успешности бизнеса, оценка благоприятности экономических условий для осуществления предпринимательской деятельности, оценка изменения уровня своей деловой активности, оценка успешности своей предпринимательской деятельности, удовлетворенность экономическими результатами предпринимательской деятельности и оценка своей деловой активности в настоящее время. С помощью кластерного анализа были выделены пять групп респондентов, различающихся сочетаниями перечисленных выше экономико-психологических характеристик, которые мы обозначили как психологические типы деловой активности предпринимателей. Сравнительный анализ результатов ранжирования значимости ценностей по методике М. Рокича показал, что для представителей всех типов деловой активности предпринимателей характерны как общие черты, так и различия в структуре терминальных и инструментальных ценностей. Для высокоактивных предпринимателей, более удовлетворенных экономическими результатами своей предпринимательской деятельности, в целом характерны более высокие оценки значимости денег, более высокие оценки надежности партнеров, более позитивное отношение к риску и конкуренции.

Ключевые слова: социальная психология, российские предприниматели, деловая активность, психологический тип, ценностные ориентации личности, интерактивная информационно-исследовательская база данных.

* Публикация подготовлена при поддержке РГНФ (проект № 15-06-12031 «Разработка и развитие интерактивной информационно-исследовательской базы данных «Социальная психология российского предпринимательства»).

This publication has been prepared with the support of the Russian Foundation for Humanities (project No. 15-06-12031 «Design and development of interactive information and research database «Social psychology of Russian entrepreneurship»). 


\section{ВВЕАЕНИЕ}

Аанное исследование является продолжением работ по развитию нового научного направления - социальной психологии российского предпринимательства, разрабатываемой в Институте психологии РАН под руководством А. А. Журавлева и В. П. Познякова (Журавлев, Позняков, 1993, 1995, 2004, 2012 и др.; Позняков, 1992, 2001, 2006 и др.; Психология предпринимательской деятельности ... , 1995; Социально-психологические исследования ... , 1999 и др.). В рамках этого направления интенсивно исследуются социально-психологические факторы деловой активности предпринимателей и успешности предпринимательской деятельности (Журавлев, Позняков, Аорофеев, 1999; Позняков, 1999 и др.). К числу наиболее существенных социально-психологических особенностей предпринимателей традиционно относят характеристики ценностно-мотивационной сферы, и в частности ценностные ориентации личности (Завьялова, Посохова, 2004; Журавлева, 2008, 2015; Позняков, 2007; Петрова, 2011 и др.). Ценностные ориентации личности предпринимателей изучались нами как факторы психологических отношений предпринимателей к деловому партнерству (Позняков, Вавакина, 2010), как факторы ответственного отношения предпринимателей к участникам делового взаимодействия (Позняков, Никуло, 2014). Вместе с тем особенности взаимосвязи ценностных ориентаций и характеристик деловой активности предпринимателей до сих пор исследованы недостаточно. Однако создание и развитие информационно-исследовательской базы данных «Социальная психология российского предпринимательства» предоставило исследователям уникальную возможность систематического обращения к результатам эмпирических исследований, проводимых рабочей группой участников проекта (Позняков, Познякова, Тихомирова, 2012; Позняков, Тихомирова, 2015 и др.).

Целью данного исследования является выявление различий в ценностных ориентациях личности у предпринимателей с разным психологическим типом деловой активности. Эмпирическое исследование проводилось в 2009 г. с участием предпринимателей сферы малого и среднего бизнеса на территории России. В общей сложности в исследовании приняли участие 106 предпринимателей, в том числе 40 женщин и 76 мужчин в возрасте от 23 до 58 лет. Основные сферы деятельности респондентов - оптовая и розничная торговля, сфера обслуживания и производство. Основным методом исследования выступало стандартизированное интервью по программе А. $\Lambda$. Журавлева и В. П. Познякова и адаптированный В. А. Ядовым вариант методики М. Рокича (Журавлев, Позняков, 2002; Журавлев, Журавлева, 2002; Позняков, 2010). В качестве характеристик деловой активности предпринимателей в данном исследовании использовались следующие показатели (в скобках римскими цифрами даны обозначения этих показателей в таблице 1): оценка собственных возможностей повышения успешности бизнеса (I), оценка благоприятности экономических условий Аля осуществления предпринимательской деятельности (II), оценка изменения уровня своей деловой активности (III), оценка успешности своей предпринимательской деятельности (IV), удовлетворенность экономическими результатами предпринимательской деятельности $(\mathrm{V})$ и оценка своей деловой активности в настоящее время (VI). Оценки по всем показателям проводились по семибалльной шкале, крайним полюсам которой соответствовали обозначения «крайне низкий»- «очень высокий уровень» оцениваемой характеристики. Оценка изменения уровня своей деловой активности проводилась по пятибалльной шкале, цифровым обозначениям которой соответствовали варианты ответов, характеризующих ретроспективную оценку изменения своей 
деловой активности и прогноз ее изменения в будущем. Выбор именно этих показателей был обусловлен тем, что на предыдущих этапах исследования они определились как наиболее существенные социально-психологические характеристики деловой активности предпринимателей. В сборе и обработке данных принимала участие выпускница факультета психологии и социальной работы Московского гуманитарного университета О. Конкина.

\section{ТИПЫ АЕАОВОЙ АКТИВНОСТИ ПРЕАПРИНИМАТЕАЕЙ}

В результате кластерного анализа были выделены пять групп респондентов, различающихся сочетаниями перечисленных выше экономико-психологических характеристик, которые мы обозначили как психологические типы деловой активности предпринимателей. В табл. 1 представлены средние значения экономико-психологических характеристик деловой активности в группах предпринимателей, выделенных с помощью кластерного анализа.

Тип активности 1 (31 респондент) - высокая оценка своей деловой активности с позитивным прогнозом ее изменения в будущем. Удовлетворенность результатами предпринимательской деятельности несколько выше средних значений. Самые высокие в выборке оценки собственных возможностей и успешности своей предпринимательской деятельности. Это предприниматели с высокой деловой активностью в настоящее время, осознающие свои большие возможности в повышении успешности бизнеса.

Таблица 1

СРЕАНИЕ ЗНАЧЕНИЯ ЭКОНОМИКО-ПСИХОАОГИЧЕСКИХ ХАРАКТЕРИСТИК

АЕ ОВОЙ АКТИВНОСТИ В ГРУППАХ ПРЕАПРИНИМАТЕАЕЙ, ВЫАЕАЕННЫХ С ПОМОЩЬЮ КААСТЕРНОГО АНААИЗА

Table 1

THE AVERAGE VALUES OF THE ECONOMIC AND PSYCHOLOGICAL CHARACTERISTICS

OF BUSINESS ACTIVITY IN THE GROUPS OF ENTREPRENEURS, SELECTED THROUGH CLUSTER ANALYSIS

\begin{tabular}{|c|c|c|c|c|c|}
\hline \multirow{2}{*}{ Очениваемые переменные } & \multicolumn{5}{|c|}{$\begin{array}{l}\text { Средние значения оченок } \\
\text { по группам респондентов }\end{array}$} \\
\hline & 1 & 2 & 3 & 4 & 5 \\
\hline $\begin{array}{l}\text { Оценка собственных возможностей повышения } \\
\text { успешности бизнеса (I) }\end{array}$ & 5,77 & 4,52 & 3,29 & 5,24 & 3,82 \\
\hline $\begin{array}{l}\text { Оценка благоприятности экономических условий } \\
\text { Аля осуществления предпринимательской } \\
\text { деятельности (II) }\end{array}$ & 4,00 & 4,17 & 2,50 & 3,62 & 2,18 \\
\hline $\begin{array}{l}\text { Оценка изменения уровня своей деловой } \\
\text { активности (III) }\end{array}$ & 4,19 & 4,35 & 3,43 & 2,38 & 2,35 \\
\hline $\begin{array}{l}\text { Оценка успешности своей предпринимательской } \\
\text { деятельности (IV) }\end{array}$ & 5,58 & 4,70 & 3,57 & 4,90 & 3,18 \\
\hline 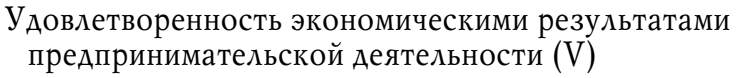 & 4,74 & 4,09 & 3,00 & 4,38 & 2,76 \\
\hline $\begin{array}{l}\text { Оценка своей деловой активности в настоящее } \\
\text { время (VI) }\end{array}$ & 5,77 & 4,17 & 5,07 & 3,90 & 2,65 \\
\hline
\end{tabular}


Тип активности 2 (23 респондента) - деловая активность оценивается несколько выше среднего уровня, с позитивным прогнозом ее изменения в будущем. Оценки собственных возможностей и успешности своей предпринимательской деятельности несколько выше средних значений. Оценки удовлетворенности экономическими результатами предпринимательской деятельности близки к средним значениям. Такой тип предпринимателей может быть охарактеризован как среднеактивный тип с позитивным прогнозом своей деловой активности.

Тип активности 3 (14 респондентов) - деловая активность оценивается выше среднего уровня, с позитивным прогнозом ее изменения в будущем. Экономические условия оцениваются скорее как неблагоприятные. Собственные возможности в повышении успешности своего бизнеса, удовлетворенность экономическими результатами и успешность своей предпринимательской деятельности оцениваются ниже среднего уровня. Такой тип по сравнению с другими может быть охарактеризован как активный, не удовлетворенный сложившимися экономическими условиями, собственными возможностями в повышении успешности бизнеса и результатами своей предпринимательской деятельности.

Тип активности 4 (21 респондент) - деловая активность средняя, но с прогнозом ее снижения в будущем. Благоприятность экономических условий оценивается немого ниже среднего уровня. При этом оценки собственных возможностей и успешности своей предпринимательской деятельности выше средних значений и выше, чем оценки удовлетворенности экономическими результатами. Это средне активный тип с негативным прогнозом своей деловой активности, представители этого типа высоко оценивают свои собственные возможности в повышении успешности бизнеса и успешность своей предпринимательской деятельности, но недостаточно удовлетворены условиями и результатами своей предпринимательской деятельности.

Тип активности 5 (17 респондентов) - самые низкие оценки уровня своей деловой активности, с тенденцией дальнейшего его снижения, не удовлетворенные экономическими условиями и результатами предпринимательской деятельности, хотя собственные возможности оцениваются на среднем уровне. Это пассивный тип без выраженных ожиданий с низкими оценками своей деловой активности и успешности предпринимательской деятельности.

Эмпирически выявленные нами психологические типы деловой активности предпринимателей соотносятся с типами экономической активности предпринимателей, выявленными в исследовании А. $\Lambda$. Журавлева и А. Б. Купрейченко (Журавлев, Купрейченко, 2009). Наиболее существенные различия между этими типами связаны с оценками их представителями уровня своей экономической активности и динамики ее изменения. Авторы обнаружили, в частности, что представители разных типов, различающиеся оценками характеристик своей деловой активности, различаются своим отношением к деньгам, что подтверждается и результатами нашего исследования.

\section{ЦЕННОСТНЫЕ ОРИЕНТАЦИИ ПРЕАПРИНИМАТЕАЕЙ С РАЗНЫМ ТИПОМ АЕАОВОЙ АКТИВНОСТИ}

Сравнительный анализ результатов ранжирования значимости ценностей по методике М. Рокича показал, что для представителей всех типов деловой активности предпринимателей характерны как общие черты, так и различия в структуре терминальных и инструментальных ценностей. Основными терминальными ценностями, 
характеризующими убеждения в том, что конечная цель индивидуального существования стоит того, чтобы к ней стремиться, стали следующие: психическое и физическое здоровье; счастливая семейная жизнь; материально обеспеченная жизнь; свобода; любовь как физическая и духовная близость с любимым человеком и наличие хороших и верных друзей. Основными инструментальными ценностями, характеризующими убеждения в том, что какой-то образ действий или свойство личности является предпочтительным в любой ситуации, оказались: честность; независимость; ответственность; образованность; воспитанность; жизнерадостность и терпимость.

В структуре терминальных ценностей выявились некоторые различия (см. табл. 2). На первом и втором месте у предпринимателей расположены «здоровье» и «семья», кроме типа 1, для которого ценность «материально обеспеченная жизнь» более значима, нежели ценность семьи. Скорее всего, это связано с тем, что представители данного типа отличаются очень высоким уровнем деловой активности, осознают свои вы-

Таблииза 2

РАНГОВАЯ СТРУКТУРА ТЕРМИНААЬНЫХ ЦЕННОСТЕЙ ПРЕАПРИНИМАТЕАЕЙ С РАЗНЫМ ТИПОМ АЕ АОВОЙ АКТИВНОСТИ*

Table 2

RANK STRUCTURE OF TERMINAL VALUES OF ENTREPRENEURS WITH DIFFERENT TYPES OF BUSINESS ACTIVITY

\begin{tabular}{|l|r|r|r|r|r|}
\hline \multicolumn{1}{|c|}{ Терминальнысе ценности } & Tun 1 & Tun 2 & Tun 3 & Tun 4 & Tun 5 \\
\hline Здоровье & 1 & 1 & 1 & 1 & 1 \\
Семья & 3 & 2 & 2 & 2 & 2 \\
Материальная обеспеченность & 2 & 4 & 3 & 4 & 3 \\
Свобода & 4 & 8 & 5 & 3 & 4 \\
Аюбовь & 7 & 3 & 8 & 5 & 5 \\
Арузья & 9 & 6 & 4 & 6 & 10 \\
Уверенность & 5 & 11 & 6 & 7 & 9 \\
Работа & 8 & 5 & 7 & 10 & 6 \\
Мудрость & 6 & 12 & 9 & 13 & 7 \\
Активная жизнь & 11 & 7 & 12 & 11 & 11 \\
Творчество & 14 & 9 & 17 & 17 & 12 \\
Познание & 12 & 10 & 11 & 9 & 8 \\
Богатство & 10 & 13 & 10 & 8 & 10 \\
Счастье других & 13 & 17 & 14 & 15 & 13 \\
Собственность & 16 & 16 & 15 & 12 & 14 \\
Бессмертие & 16 & 18 & 13 & 14 & 17 \\
Развлечения & 15 & 14 & 16 & 16 & 18 \\
Красота & 17 & 15 & 18 & 18 & 15 \\
\hline
\end{tabular}

* В таблице приведены приписанные ранги, в основе которых лежат средние ранговые значения. 
сокие возможности в бизнесе и поэтому в большей степени стремятся улучшить свое материальное благосостояние. Третье место как у высоко активных, так и у неактивных предпринимателей занимает такая ценность, как «материальная обеспеченность», а у средне активных на третьем месте такие ценности, как «любовь» (2-й тип) и «свобода» (4-й тип). Скорее всего, это может быть связанно с тем, что более важной целью представителей средне активных типов является улучшение качества личной жизни. Об этом говорят также более высокие ранги у представителей этих групп ценности «друзья». Отличительными особенностями низко активных предпринимателей являются более высокие, чем в большинстве других групп, ранги ценностей «познание», «мудрость» и «творчество».

Также были выявлены некоторые различия в структуре инструментальных ценностей (см. табл. 3). На первом и втором месте у предпринимателей расположены «честность» и «ответственность», кроме типа 4, для представителей которого ценность

Таблица 3

РАНГОВАЯ СТРУКТУРА ИНСТРУМЕНТААЬНЫХ ЦЕННОСТЕЙ ПРЕАПРИНИМАТЕАЕЙ

С РАЗНЫМ ТИПОМ АЕАОВОЙ АКТИВНОСТИ*

Table 3

RANK STRUCTURE OF INSTRUMENTAL VALUES OF ENTREPRENEURS WITH DIFFERENT TYPES OF BUSINESS ACTIVITY

\begin{tabular}{|l|r|r|r|r|r|}
\hline \multicolumn{1}{|c|}{ Инструментальные уенности } & Tun 1 & Tun 2 & Tun 3 & Tun 4 & Tun 5 \\
\hline Честность & 1 & 1 & 1 & 1 & 1 \\
Ответственность & 2 & 2 & 2 & 4 & 2 \\
Независимость & 3 & 7 & 3 & 2 & 3 \\
Образованность & 4 & 3 & 9 & 3 & 5 \\
Жизнерадостность & 6 & 8 & 8 & 5 & 4 \\
Самоконтроль & 11 & 12 & 6 & 11 & 8 \\
Эффективность в делах & 5 & 10 & 4 & 8 & 10 \\
Терпимость & 13 & 5 & 5 & 10 & 7 \\
Воспитанность & 12 & 9 & 12 & 6 & 6 \\
Богатство & 7 & 13 & 11 & 7 & 9 \\
Твердая воля & 8 & 6 & 10 & 13 & 11 \\
Предприимчивость & 10 & 4 & 13 & 9 & 15 \\
Смелость в отстаивании взглядов & 9 & 16 & 7 & 12 & 19 \\
Широта взглядов & 14 & 11 & 15 & 15 & 12 \\
Рационализм & 16 & 14 & 18 & 16 & 14 \\
Собственность & 17 & 18 & 14 & 14 & 17 \\
Исполнительность & 15 & 17 & 17 & 18 & 13 \\
Чуткость & 18 & 15 & 16 & 17 & 16 \\
Непримиримость к недостаткам других & 19 & 19 & 19 & 19 & 18 \\
\hline
\end{tabular}

* В таблице приведены приписанные ранги, в основе которых лежат средние ранговые значения. 
«независимость» более значима, нежели «ответственность». Скорее всего, это связано с тем, что представители этого типа средне удовлетворены условиями и результатами экономической деятельности, им больше требуется свободы, и средством для достижения данной цели является такая ценность, как независимость. Неудовлетворенность в достижении этой цели может выступать одной из причин прогноза снижения своей деловой активности в будущем. Отличительными особенностями представителей этого типа являются самые низкие по выборке оценки значимости ценности «работа» и самые высокие - ценности «собственность». Третье место у высокоактивных и неактивных предпринимателей занимает «независимость», а у средне активных на третьем месте «образованность». Скорее всего, это может быть связано с тем, что для достижения своих целей в предпринимательской деятельности средне активные предприниматели больше полагаются на определенные знания в данной области деятельности.

Среди ценностей, занявших 4-6-е место, также обнаружились различия в их значимости в зависимости от типа активности. Так, для представителей 1-го типа (высоко активный) важны такие ценности, как «образованность», «эффективность в делах», «жизнерадостность»; для представителей 2-го типа активности (средне активный) важны такие ценности, как «предприимчивость», «терпимость», «твердая воля»; для представителей 3-го типа активности (активный) важны такие ценности, как «эффективность в делах», «терпимость», «самоконтроль»; для представителей 4-го типа активности (средне активный): «ответственность», «жизнерадостность», «воспитанность»; для представителей 5-го типа активности (неактивный): «жизнерадостность», «образованность», «воспитанность». Отличительными особенностями высоко активных предпринимателей являются более высокие, чем в большинстве других групп, ранги ценностей «эффективность в делах», «богатство» и «твердая воля». Отличительными особенностями низкоактивных предпринимателей являются более высокие, чем в большинстве других групп, ранги ценностей «жизнерадостность», «воспитанность» и «широта взглядов».

\section{АИЧНОСТНЫЕ ОРИЕНТАЦИИ ПРЕАПРИНИМАТЕАЕЙ \\ С РАЗНЫМ ТИПОМ АЕАОВОЙ АКТИВНОСТИ}

Сопоставление личностных ориентаций в предпринимательской деятельности у представителей выделенных нами психологических типов деловой активности позволило сделать вывод о том, что каждому типу соответствуют свои личностные преАпочтения в предпринимательской деятельности (см. табл. 4). Так, для всех типов активности, кроме типа 3, наиболее значимы такие мотивы выбора предпринимательской деятельности, как материальная обеспеченность, независимость и самостоятельность в работе, возможность реализовать свои способности. Что же касается 3-го типа, Аля него такие мотивы, как независимость и самостоятельность в работе и возможность реализовать свои способности, более актуальны, чем материальная обеспеченность. Скорее всего, это может быть связанно с его неудовлетворенностью сложившимися экономическими условиями и результатами предпринимательской деятельности, а также с ограниченными возможностями в повышении успешности бизнеса.

Стоит обратить внимание на тот факт, что для высокоактивных предпринимателей, более удовлетворенных экономическими результатами своей предпринимательской деятельности, в целом характерны более высокие оценки значимости денег, более высокие оценки надежности партнеров, более позитивное отношение к риску и конку- 
Таблииа 4

РАСПРЕАЕАЕНИЕ АИЧНОСТНЫХ ОРИЕНТАЦИЙ РЕСПОНАЕНТОВ

В ПРЕАПРИНИМАТЕАЬСКОЙ АЕЯТЕАЬНОСТИ

Table 4

THE DISTRIBUTION OF THE PERSONAL ORIENTATIONS OF THE RESPONDENTS

IN BUSINESS

\begin{tabular}{|c|c|c|c|c|c|c|c|c|c|c|}
\hline \multirow{2}{*}{\begin{tabular}{|c|} 
Очениваемые \\
переменные \\
Значимость \\
мотивов выбора предпри- \\
нимательской деятельно- \\
сти
\end{tabular}} & \multicolumn{2}{|c|}{ Tun 1} & \multicolumn{2}{|c|}{ Tun 2} & \multicolumn{2}{|c|}{ Tun 3} & \multicolumn{2}{|c|}{ Tun 4} & \multicolumn{2}{|c|}{ Tun 5} \\
\hline & $\begin{array}{l}\text { Сред. } \\
\text { знач. }\end{array}$ & Ранг & $\begin{array}{l}\text { Сред. } \\
\text { знач. }\end{array}$ & Ранг & $\begin{array}{l}\text { Сред. } \\
\text { знач. }\end{array}$ & Ранг & $\begin{array}{l}\text { Сред. } \\
\text { знач. }\end{array}$ & Ранг & $\begin{array}{l}\text { Сред. } \\
\text { знач. }\end{array}$ & Ранг \\
\hline $\begin{array}{l}\text { Независимость } \\
\text { и самостоятель- } \\
\text { ность в работе }\end{array}$ & 2,25 & 2 & 2,19 & 2 & 2,10 & 1 & 2,35 & 2 & 2,14 & 2 \\
\hline $\begin{array}{l}\text { Возможность } \\
\text { реализовать свои } \\
\text { способности }\end{array}$ & 2,67 & 3 & 2,47 & 3 & 3,17 & 2 & 2,45 & 3 & 3,08 & 3 \\
\hline $\begin{array}{l}\text { Материальная } \\
\text { обеспеченность }\end{array}$ & 2,19 & 1 & 2,04 & 1 & 2,53 & 3 & 2,11 & 1 & 1,79 & 1 \\
\hline $\begin{array}{l}\text { Полезность рабо- } \\
\text { ты для других } \\
\text { людей }\end{array}$ & 4,96 & 6 & 4,71 & 5 & 4,53 & 5 & 4,88 & 6 & 4,38 & 4 \\
\hline $\begin{array}{l}\text { Авторитет у окру- } \\
\text { жающих }\end{array}$ & 4,06 & 4 & 4,5 & 4 & 3,82 & 4 & 4,30 & 4 & 4,44 & 5 \\
\hline $\begin{array}{l}\text { Возможность об- } \\
\text { щаться с интерес- } \\
\text { ными людьми }\end{array}$ & 4,77 & 5 & 5,06 & 6 & 4,82 & 6 & 4,73 & 5 & 5,14 & 6 \\
\hline & \multicolumn{2}{|c|}{ Сред. знач. } & \multicolumn{2}{|c|}{ Сред. знач. } & \multicolumn{2}{|c|}{ Сред. знач. } & \multicolumn{2}{|c|}{ Сред. знач. } & \multicolumn{2}{|c|}{ Сред. знач. } \\
\hline $\begin{array}{l}\text { Отношение к кон- } \\
\text { куренции }\end{array}$ & \multicolumn{2}{|c|}{3,77} & \multicolumn{2}{|c|}{3,43} & \multicolumn{2}{|l|}{$J$} & \multicolumn{2}{|c|}{3,04} & \multicolumn{2}{|c|}{2,7} \\
\hline Отношение к риску & \multicolumn{2}{|c|}{2,64} & \multicolumn{2}{|c|}{2,34} & \multicolumn{2}{|c|}{2,5} & \multicolumn{2}{|c|}{2,23} & \multicolumn{2}{|c|}{2,4} \\
\hline Значение денег & \multicolumn{2}{|l|}{6} & \multicolumn{2}{|c|}{5,78} & \multicolumn{2}{|c|}{5,5} & \multicolumn{2}{|c|}{5,42} & \multicolumn{2}{|c|}{5,05} \\
\hline $\begin{array}{l}\text { Надежность парт- } \\
\text { неров }\end{array}$ & \multicolumn{2}{|c|}{5,25} & \multicolumn{2}{|c|}{4,91} & \multicolumn{2}{|c|}{4,2} & \multicolumn{2}{|c|}{4,8} & \multicolumn{2}{|c|}{3,88} \\
\hline
\end{tabular}

ренции. Однако встречаются и исключения. Так, представители 3-го типа, хоть это и активный тип предпринимателей, гораздо менее позитивно относятся к конкуренции и менее склонны доверять своим партнерам. Закономерно, что низко активные предприниматели, не удовлетворенные экономическими результатами своей предпринимательской деятельности, более негативно относятся к риску и конкуренции в предпринимательской деятельности и более низко оценивают надежность своих партнеров по бизнесу. 


\section{ЗАКАЮЧЕНИЕ}

В результате проведенного исследования эмпирически выделены группы предпринимателей, различающихся оценками экономико-психологических характеристик своей деловой активности. Аля представителей всех типов деловой активности предпринимателей характерны как общие черты, так и различия в структуре терминальных и инструментальных ценностей. Результаты исследования согласуются с представленными нами ранее данными о различиях в структуре ценностных ориентаций у предпринимателей с разным уровнем деловой активности (Позняков, 2013) и уточняют их. Таким образом, мы можем говорить о том, что предпринимателям, различающимся типом деловой активности, присущи свои определенные личностные и ценностные ориентации, направленные на удовлетворение собственных потребностей и достижение успеха в предпринимательской деятельности и зависящие от удовлетворенности экономическими условиями, оценки собственных возможностей, успешности своей предпринимательской деятельности и удовлетворенности ее результатами.

\section{СПИСОК АИТЕРАТУРЫ}

Журавлев, А. А., Журавлева, Н. А. (2002) Программа социально-психологического исследования экономического сознания личности // Современная психология: состояние и перспективы исследований : в 5 ч. / отв. ред. А. $\Lambda$. Журавлев. М. : Изд-во «Институт психологии РАН». Ч. 5.368 с. С. $11-41$.

Журавлев, А. А., Купрейченко, А. Б. (2009) Отношение к деньгам предпринимателей с различным психологическим типом экономической активности // Психология и экономика. Т. 2. № 1. C. 12-32.

Журавлев, А. А., Позняков, В. П. (1993) Социально-психологические трудности становления малого бизнеса в России // Психологический журнал. Т. 14. № 6. С. 23-34.

Журавлев, А. А., Позняков, В. П. (1995) Аеловая активность предпринимателей: методы оценки и воздействия. М. : Изд-во «Институт психологии РАН». 58 с.

Журавлев, А. А., Позняков, В. П. (2002) Программа социально-психологического исследования российских предпринимателей // Современная психология: состояние и перспективы исследований : в 5 ч. / отв. ред. А. А. Журавлев. М. : Изд-во «Институт психологии РАН». Ч. 5. 368 с. С. $90-110$.

Журавлев, А. А., Позняков, В. П. (2004) Экономическая психология: теоретические проблемы и направления эмпирических исследований // Психология. Журнал Высшей школы экономики. Т. 1. № 3. С. 46-64.

Журавлев, А. А., Позняков, В. П. (2012) Социальная психология российского предпринимательства: Концепция психологических отношений. М. : Изд-во «Институт психологии РАН». $480 \mathrm{c}$.

Журавлев, А. А., Позняков, В. П., Аорофеев, Е. А. (1999) Социально-психологические факторы деловой активности и успешность деятельности предпринимателей // Социально-психологические исследования руководства и предпринимательства / отв. ред. А. . Журавлев, Е. В. Шорохова. М. : Изд-во «Институт психологии РАН». 276 с. С. 44-67.

Журавлева, Н. А. (2008) Ценностные ориентации предпринимателей в изменяющемся российском обществе // Вестник РУАН. Серия. Психология и педагогика. № 1. С. 46-49.

Журавлева, Н. А. (2015) Аинамика ценностных ориентаций предпринимателей в условиях макросоциальных преобразований // Психологический журнал. Т. 36. № 1. С. 46-60.

Завьялова, Е. К., Посохова, С. Т. (2004) Психология предпринимательства : учеб. пособие. СПб. : ИзА-во СПбГУ. 296 с.

Петрова, Н. И. (2011) Ценностно-смысловая сфера личности руководителей государственной службы и предпринимателей // Психологический журнал. № 1. С. 34-44. 
Позняков, В. П. (1992) Новая социальная группа: признаки, мотивы действий, трудности становления // Человек и труд. № 4-5. С. 14-17.

Позняков, В. П. (1999) Региональные особенности психологических отношений российских предпринимателей к своей деятельности // Социально-психологические исследования руководства и предпринимательства / отв. ред. А. А. Журавлев, Е. В. Шорохова. М. : ИзА-во «Институт психологии $\mathrm{PAH».} 276$ с. С. $68-89$.

Позняков, В. П. (2001) Психологические отношения и деловая активность российских предпринимателей. М. : ИзА-во «Институт психологии РАН». 240 с.

Позняков, В. П. (2006) Социальная психология предпринимательства: состояние исследова-

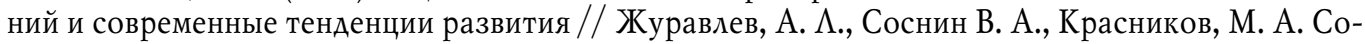
циальная психология : учеб. пособие. М. : Форум ; ИНФРА-М. 416 с. С. 392-410.

Позняков, В. П. (2007) Предпринимательство как ценность и ценности российских предпринимателей // Россия в глобализирующемся мире: мировоззренческие и социокультурные аспекты / отв. ред. В. С. Степин. М. : Наука. 640 с. С. 513-528.

Позняков, В. П. (2010) Программы и методики социально-психологического исследования российских предпринимателей. М. : Изд-во МосГУ. 188 с.

Позняков, В. П. (2013) Социально-психологические характеристики российских предпринимателей с разным уровнем деловой активности // Знание. Понимание. Умение. № 4. С. 212-220.

Позняков, В. П., Вавакина, Т. С. (2010) Взаимосвязь психологических отношений предпринимателей к деловому партнерству и их ценностных ориентаций // Социальная психология труда: Теория и практика : в 2 т. / отв. ред. А. А. Журавлев, $\Lambda$. Г. Аикая. М. : Изд-во «Институт психологии РАН». Т. 2. 442 с. С. 397-420.

Позняков, В. П., Никуло, Е. А. (2014) Ценностные ориентации как фактор ответственного отношения предпринимателей к участникам делового взаимодействия // Человеческий фактор проблемы психологии и эргономики. № 4 (71). С. 22-31.

Позняков, В. П., Познякова, Н. Н., Тихомирова, С. В. (2012) Социальная психология российского предпринимательства. Разработка информационно-исследовательской базы данных // Знание. Понимание. Умение. № 4. С. 227-234.

Позняков, В. П., Тихомирова, С. В. (2015) Интерактивная информационно-исследовательская база данных «Социальная психология российского предпринимательства» // Знание. Понимание. Умение. № 1. С. 206-212.

Психология предпринимательской деятельности (Развитие российского предпринимательства в начале 1990-х гг.) (1995) / под общ. ред. В. А. Бодрова. М. : ИПРАН. 175 с.

Социально-психологические исследования руководства и предпринимательства (1999)/ отв. ред. А. А. Журавлев, Е. В. Шорохова. М. : ИзА-во «Институт психологии РАН». 276 с.

Аата поступления: 11.06.2015 2.

\section{VALUE ORIENTATIONS IN ENTREPRENEURS WITH VARIOUS TYPES OF BUSINESS ACTIVITY \\ V. P. POZNIAKOV}

(INSTITUTE OF PSYCHOLOGY, RUSSIAN ACADEMY OF SCIENCES; MOSCOW UNIVERSITY FOR THE HUMANITIES)

The article presents the research outcomes of a study of value orientations in entrepreneurs with various types of business activity. The study was conducted in 2009, polling 106 entrepreneurs. We used the following indicators as the characteristics of entrepreneurs' business activity, including assessments of: one's capability to make their business more successful; of favorability of economic conditions for doing business; of changes in the level of one's business activity; of success as a businessman; of achievement satisfaction; and of current business operations. With the help of cluster analysis we have classified respondents into 5 groups with differing combinations of the abovementioned economic and psychological characteristics that we have identified as types of the entrepreneurs' business activity. A comparative analysis of ranking the values by their importance (the 
M. Rokich method) showed that all types of entrepreneurs' business activity share both similarities and differences in the structure of terminal and instrumental values. High-level entrepreneurs who are more satisfied with their enterprise generally show higher estimates of the importance of money, of partner reliability, as well as a more positive attitude towards risk and competition.

Keywords: social psychology, Russian entrepreneurs, business activity, value orientation, interactive information and research database

\section{REFERENCES}

Zhuravlev, A. L. and Zhuravleva, N. A. (2002) Programma sotsial'no-psikbologicheskogo issledovaniia ekonomicheskogo soznaniia lichnosti [The program of socio-psychological research of economic consciousness of the person] In: Sovremennaia psikbologiia: sostoyanie i perspektivyi issledovanii [Modern psychology: status and prospects of research] : in 2 vols. / ed. by A. L. Zhuravlev. Moscow, Publishing House of the Institute of Psychology, RAS. Vol. 5. 368 p. Pp. 11-41. (In Russ.).

Zhuravlev, A. L. and Kupreychenko, A. B. (2009) Otnosbenie $k$ den'gam predprinimatelei $s$ razlichnym psikbologicheskim tipom ekonomicheskoi aktivnosti [Attitudes towards money in the entrepreneurs with different psychological types of economic activity]. Psikbologiia $i$ ekonomika [Psychology and Economics], vol. 2, no. 1, pp. 12-32. (In Russ.).

Zhuravlev, A. L. and Pozniakov, V. P. (1993) Sotsial'no-psikhologicheskie trudnosti stanovleniia malogo biznesa v Rossii (analiz gruppovogo mneniia predprinimatelei) [Socio-psychological difficulties of the rise of small business in Russia (an analysis of entrepreneurs' group opinion)]. Psikbologicheskii zhurnal, vol. 14, no. 6. pp. 23-34. (In Russ.).

Zhuravlev, A. L. and Pozniakov, V. P. (1995) Delovaia aktivnost' predprinimatelei: metody otsenki $i$ vozdeistviia [Business activities of entrepreneurs: Methods of evaluation and impact]. Moscow, Publishing House of the Institute of Psychology, RAS. 58 p. (In Russ.).

Zhuravlev, A. L. and Pozniakov, V. P. (2002) Programma sotsial'no-psikhologicheskogo issledovaniia rossiiskih predprinimatelei [A program of socio-psychological research of Russian entrepreneurs] In: Sovremennaia psikbologiia: sostoianie i perspektivyi issledovanii [Modern psychology: status and prospects of research]: in 2 vols. / ed. by A. L. Zhuravlev. Moscow, Publishing House of the Institute of Psychology, RAS. Vol. 5. 368 p. Pp. 90-110. (In Russ.).

Zhuravlev, A. L. and Pozniakov, V. P. (2004) Ekonomicheskaia psikhologiia: teoreticheskie problemy i napravleniia empiricheskikh issledovanii [Economic psychology: theoretical problems and directions of empirical studies]. Psikbologiia. Zhurnal Vysshei shkoly ekonomiki, vol. 1, no. 3, pp. 46-64. (In Russ.).

Zhuravlev, A. L. and Pozniakov, V. P. (2012) Sotsial naia psikbologiia rossiiskogo predprinimatel'stva: Kontseptsiia psikbologicheskikb otnoshenii [Social psychology of Russian entrepreneurship: the concept of psychological relations]. Moscow, Publishing House of the Institute of Psychology, RAS. 480 p. (In Russ.).

Zhuravlev, A. L., Pozniakov, V. P. and Dorofeev, E. D. (1999) Sotsial'no-psikhologicheskie factory delovoi aktivnosti i uspeshnost' predprinimatel'skoi deiatel'nosti [Socio-psychological factors of business activity and the success of entrepreneurs activity]. In: Sotsial'no-psikbologicheskie issledovaniia rukovodstva i predprinimatel'stva [Socio-psychological studies of leadership and entrepreneurship] (1999)/ ed. by A. L. Zhuravlev and E.V. Shorokhova. Moscow, Publishing House of the Institute of Psychology, RAS. 276 p. Pp. 44-67 (In Russ.).

Zhuravleva, N. A. (2008) Tsennostnyie orientatsii predprinimatelei v izmeniaiushchemsia rossiiskom obshchestve [Value orientations of entrepreneurs in the developing Russian society]. Vestnik RUDN. Seriia: Psikbologiia i pedagogika, no. 1, pp. 46-49. (In Russ.).

Zhuravleva, N. A. (2015) Dinamika tsennostnyh orientatsii predprinimatelei v usloviyah makrosocal'nyh preobrazovanii [Businessmen value orientations dynamics in conditions of macrosocial changes]. Psikbologicheskii zhurnal, vol. 36, no. 1, pp. 46-60. (In Russ.).

Zav'ialova, E. K., Posokhova, S. T. (2004) Psikbologiia predprinimatel'stva [Psychology of Entrepreneurship]. St. Petersburg, St. Petersburg State University Publ. 296 p. (In Russ.). 
Petrova, N. A. (2011) Tsennostno-smyslovaya sfera lichnosti rukovoditelei gosudarstvennoi sluzhby i predprinimatelei [Value-semantic sphere of the personality of public service leaders and entrepreneurs]. Psikbologicheskii zhurnal, vol. 32. no. 1, pp. 34-44. (In Russ.).

Pozniakov, V. P. (1992) Novaia sotsial'naia gruppa: priznaki, motivy deistvii, trudnosti stanovleniia [The new social group: characteristics, motives for action, emergence issues]. Chelovek $i$ trud, no. 4-5, pp. 14-17. (In Russ.).

Pozniakov, V. P. (1999) Regional'nyie osobennosti psikhologicheskih otnoshenii rossiiskih predprinimatelei k svoei deiatelnosti [Regional features of psychological relations of Russian entrepreneurs in their activities]. In: Sotsial'no-psikbologicheskie issledovaniia rukovodstva $i$ predprinimatel'stva [Socio-psychological studies of the Leadership and Entrepreneurship]/ ed. by A. L. Zhuravlev and E. V. Shorokhova. Moscow, Publishing House of the Institute of Psychology, RAS. 276 p. Pp. 68-89. (In Russ.).

Pozniakov, V. P. (2001) Psikbologicheskiie otnosheniia i delovaia aktivnost' rossiiskikh predprinimatelei [Psychological Relations and business activity of Russian entrepreneurs]. Moscow, Publishing House of the Institute of Psychology, RAS. 240 p. (In Russ.).

Poznyakov, V. P. (2006) Sotsial'naia psikhologiia predprinimatel'stva: sostoianiie issledovanii i sovremennyie tendentsii razvitiia [Social psychology of entrepreneurship: The current state of research and contemporary trends]. In: Zhuravlev, A. L., Sosnin, V. A. and Krasnikov, M. A. Sotsial'naia psikbologiia [Social Psychology]. Moscow, Forum Publ., INFRA-M Publ. 416 p. Pp. 392-410. (In Russ.).

Pozniakov, V. P. (2007) Predprinimatel'stvo kak tsennost' i tsennosti rossiiskikh predprinimatelei [Entrepreneurship as a value and values of Russian entrepreneurs]. In: Rossiia $v$ globaliziruiushchemsia mire: mirovozzrencheskie $i$ sotsiokul'turnye aspekty [Russia in the globalizing world : the paradigmal and socio-cultural aspects] / ed. by V.S. Stepin. Moscow, Nauka. 640 p. Pp. 513-528. (In Russ.).

Pozniakov, V. P. (2010) Programmy i metodiki sotsial' no-psikbologicheskogo issledovaniia rossiiskih predprinimatelei [Programs and methods of socio-psychological study of Russian entrepreneurs]. Moscow, Moscow University for the Humanities Publ. 188 p. (In Russ.).

Poznyakov, V. P. (2013) Sotsia'lno-psikhologicheskiie harakteristiki rossiyskih predprinimatelei $s$ raznym urovnem delovoi aktivnosti [Socio-psychological characteristics of Russian entrepreneurs with different levels of business activity]. Znanie. Ponimanie. Umenie, no. 4, pp. 212-220. (In Russ.).

Poznyakov, V. P. and Vavakina, T. S. (2010) Vzaimosviaz' psichologicheskich otnoshenii predprinimatelei $\mathrm{k}$ delovomu partnerstvu i ich tsennostnyich orientatsii [The relationship between the psychological attitudes of entrepreneurs to business partnership and their value orientations]. In: Sotsialnaya psichologiya truda: Teoriya $i$ praktika [Social Psychology of Work : Theory and practice] : in 2 vols. / ed. by A. L. Zhuravlev, L. G. Dikaya. Moscow, Publishing House of the Institute of Psychology, RAS. Vol. 2. 442 p. Pp. 397-420. (In Russ.).

Pozniakov, V. P., and Nikulo, E. A. (2014) Tsennostnyie orientatsii kak faktor otvetstvennogo otnosheniya predprinimateley $\mathrm{k}$ uchastnikam delovogo vzaimodeystviya [Value orientation as a factor of responsible attitude of entrepreneurs to the participants of business interaction]. Chelovecheskiy faktor problemy psibologii i ergonomiki, no. 4 (71), pp. 22-31. (In Russ.).

Pozniakov, V. P., Pozniakova, N. N. and Tihomirova, S. V. (2012) Sotsial'naia psikhologiia rossiiskogo predprinimatel'stva. Razrabotka informatsionno-issledovatel'skoi bazy dannyh [The social psychology of Russian entrepreneurship. Developing an information and research database]. Znanie. Ponimanie. Umenie, no. 4, pp. 226-234. (In Russ.).

Pozniakov, V. P. and Tihomirova, S. V. (2015) Interaktivnaya informatsionno-issledovatel'skaia baza dannyih «Sotsialnaia psihologiia rossiyskogo predprinimatel'stva» [Interactive information and research database «Social psychology of Russian entrepreneurship»]. Znanie. Ponimanie. Umenie, no. 1, pp. 206-212. (In Russ.).

Psikbologiia predprinimate'lskoi deyatel'nosti (Razvitie rossiyskogo predprinimatel'stva $v$ nachale 1990-b gg.) (1995) [Psychology of entrepreneurship (Development of Russian business in early 1990s)]/ ed. by V. A. Bodrov. Moscow, Institute of Psychology, RAS. 175 p. (In Russ.). 
Sotsial'no-psikbologicheskie issledovaniia rukovodstva $i$ predprinimatel'stva [Socio-psychological studies of leadership and entrepreneurship] (1999) / ed. by A. L. Zhuravlev and E. V. Shorokhova. Moscow, Publishing House of the Institute of Psychology, RAS. 276 p. (In Russ.).

Submission date: 11.06 .2015$.

Позняков Владимир Петрович - доктор психологических наук, главный научный сотрудник лаборатории социальной и экономической психологии Института психологии РАН, член-корреспондент Международной академии психологических наук. Адрес: 129366, Россия, г. Москва, ул. Ярославская, д. 13. Тел./факс: +7 (495) 682-72-70. Эл. адрес: pozn_v@mail.ru

Pozniakov Vladimir Petrovich, Doctor of Psychology, Chief research fellow, Laboratory of social and economic psychology, Institute of Psychology, Russian Academy of Sciences; corresponding member, International Academy of Psychological Science (IAPS). Postal address: 13 Yaroslavskaya St., 129366 Moscow, Russian Federation. Tel./fax: +7 (495) 682-72-70. E-mail: pozn_v@mail.ru 